\title{
Rehabilitación del edificio Aita Agirre en Elgoibar, Guipuzcoa
}

Jovino Martínez Sierra

Dr. Arquitecto

\section{RESUMEN:}

El proyecto consiste en la rehabilitación de las antiguas escuelas Aita Agirre para crear un nuevo centro que albergue las distintas actividades culturales de Elgoibar. La intervención conserva los muros de piedra del edificio histórico y vacía su interior, dejando un contenedor en el que crear una nueva arquitectura con un esquema organizativo flexible y de conexión entre las distintas partes. La distribución de usos tiene en cuenta la relación del edificio con la plaza Aita Agirre, y la graduación público - privado, ruidoso - silencioso, que se produce a medida que nos adentramos en el edificio y hacia las plantas superiores. El proyecto respeta la imagen y memoria histórica creando una arquitectura contemporánea, sostenible y eficiente.

\section{ABSTRACT:}

The project starts with the old village school restoration to create a new cultural center in the main square of Elgoibar. The intervention preserves historical building stone walls, leaving its facades as a container where we develop the project, creating a new architecture with a flexible layout, connecting areas and functions. The program distribution takes care about the relationship between the building and the square "Aita Agirre" and the sequence: public space - private space, noisy space - silent space, which happens while we get inside the building. This project respects the historical image of the building creating a new contemporary efficient sustainable architecture. 
El edificio actual consta de dos partes, el edificio histórico y un anexo posterior. El conjunto presenta tres fachadas visibles desde la plaza principal de Elgoibar, con un porche porticado que sirve de acceso al edificio. Actualmente se conserva la estructura original de muros de carga de mampostería, los forjados y cubierta de madera en un estado degradado y las fachadas de piedra natural combinada con mampostería y revoco de mortero con pintura. El edificio existente tiene una superficie útil de 1911,16 m2. El edificio Aita Agirre es de propiedad municipal que se encuentra incluido en el "Catálogo de bienes protegidos" en el Plan General de Ordenación Urbana de Elgoibar.

El Ayuntamiento de Elgoibar va a rehabilitarlo para acoger diversos usos relacionados con la actividad cultural del Municipio. El proyecto define las obras de adecuación y nueva redistribución de los espacios para acoger los nuevos usos. El edificio da frente a la plaza Aita Agirre con una estructura simétrica de fachada y cubiertas a conservar y rehabilitar, interviniendo en el interior para conseguir espacios polivalentes y flexibles que permitan adaptarse a las diferentes necesidades de programa.

\section{Historia}

El edificio Aita Agirre se construyó en el año 1925. Inicialmente albergó la escuela de artes y oficios de Elgoibar, y posteriormente la alhóndiga y las antiguas escuelas de parvularios en planta baja mientras que la planta alta se destinaba a viviendas. En el año 1949 se amplió la alhóndiga con el anexo que existe en la fachada posterior. En los años 1963-64, se acondicionaron aulas en la planta baja, ampliando con un anexo en la fachada posterior, tal y como existe actualmente.

En 1980, al construirse un nuevo edificio escolar, se dejó de usar éste como tal, y desde entonces se han ubicado en él diferentes asociaciones culturales del municipio: Euskaltegi AEK, taller de pintura, escuela de cerámica, Cruz Roja, y otras asociaciones municipales no lucrativas.

El edificio se completó en la parte posterior con dos ampliaciones en planta baja, ejecutadas en los años 1949 y 1962 respectivamente que se adosaron en la parte posterior. Ambas ampliaciones no presentan continuidad en la altura de sus cubiertas, existiendo una diferencia de cotas de $0.71 \mathrm{~m}$.

\section{Intervención}

La rehabilitación adecuará la envolvente del edificio para mejorar significativamente la eficiencia energética, minimizando los consumos del inmueble, y minimizando las emisiones de C02, según una rehabilitación sostenible. Se rehabilitará el edificio histórico y se creará en el anexo posterior, un volumen destinado a espacios de instalaciones y núcleo de escaleras, creando una terraza transitable que revitalizará el actual espacio degradado.

La rehabilitación del Aita Agirre se plantea desde la vocación de realizar un equipamiento comunitario del municipio de Elgoibar, con el objetivo de acoger diversos usos relacionados con la actividad cultural del municipio, y por tanto con una definida vocación pública y social. El proyecto de rehabilitación propone una solución que responde a 4 cuestiones:

- Cómo hacer compatible el carácter histórico y unitario del edificio con una nueva intervención contemporánea.

- Cómo definir un edificio versátil concebido para dar cabida a un programa complejo y con una vocación flexible y polivalente.

- Cómo dar respuesta al programa aportando calidad espacial a los nuevos usos.

- Cuál debe ser la relación del edificio con el contexto urbano.

\section{Contexto}

El edificio tiene una clara vocación cívica que genera y tiene una importante relación con el espacio urbano. El Aita Agirre se abre a la plaza desde el pórtico de acceso y hacia el interior en el vestíbulo como prolongación del espacio público que coloniza el edificio a través de las diferentes plantas. Los espacios interiores están vinculados con vistas al espacio público y diagonales visuales desde las diferentes plantas a la plaza.

Transformación contemporánea: Intervenir en un edificio histórico exige tomar postura sobre su transformación en el espacio y en el tiempo, evitando una intervención conservadora. Conservar las fachadas y el volumen y transformar el interior con una arquitectura contemporánea y flexible.

Flexibilidad: Todas las plantas tienen como punto fijo el núcleo de comunicaciones en el eje. Todo lo demás es capaz de ser modificado a 
lo largo del tiempo. Proponemos un edificio de usos sociales y culturales con espacios fluidos e interconectados.

Organización espacial: Proponemos un edificio elaborado desde un pensamiento y una construcción lógica. Articulamos espacial y funcionalmente el edificio con un funcionamiento versátil y adaptable, conectando los diferentes usos del programa.

\section{Programa}

El vestíbulo se convierte en un espacio sorprendente y polivalente, capaz de albergar el área de acceso y espera, reuniones y hasta actos y pequeñas representaciones, articulando la planta baja con la planta primera mediante un graderío.

El kafe antzokia se proyecta en planta baja con posibilidad de acceso independiente al resto del edificio. Se podrá conectar eventualmente con la sala polivalente de planta baja mediante un panel móvil, de manera que se podrá aumentar su aforo para espacios dedicados a actividades, proyecciones, conciertos, etc.
Las salas polivalentes se sitúan en la planta baja, conectando el kafe antzokia y el vestíbulo, $\mathrm{y}$ en la planta primera, espacio polivalente para conferencias, actos, etc. y el graderío que conecta el vestíbulo y la planta primera.

La biblioteca es uno de los espacios protagonistas del edificio. Situado en el eje de la fachada de la planta segunda y de doble altura, el espacio se une visualmente con el bajocubierta, manteniendo la independencia acústica con óptimas condiciones espaciales y de iluminación. Se establece una relación visual desde la última planta hasta el espacio público. El área de biblioteca dispone también de una zona de consulta de libros infantil, una sala de estudio, y tres salas de trabajo.

La sala de ordenadores, con área de clases y consultas se proyecta en planta primera.

“Udal euskaltegia”. Situado en la planta bajocubierta se proyectan cuatro aulas, despacho y sala de reunión para la enseñanza del Euskera.

"Elgoibarko izarra." La asociación se ubicará en la planta bajocubierta, donde dispondrá de espacio de atención y trabajo para centralizar todos los servicios que ofrece.

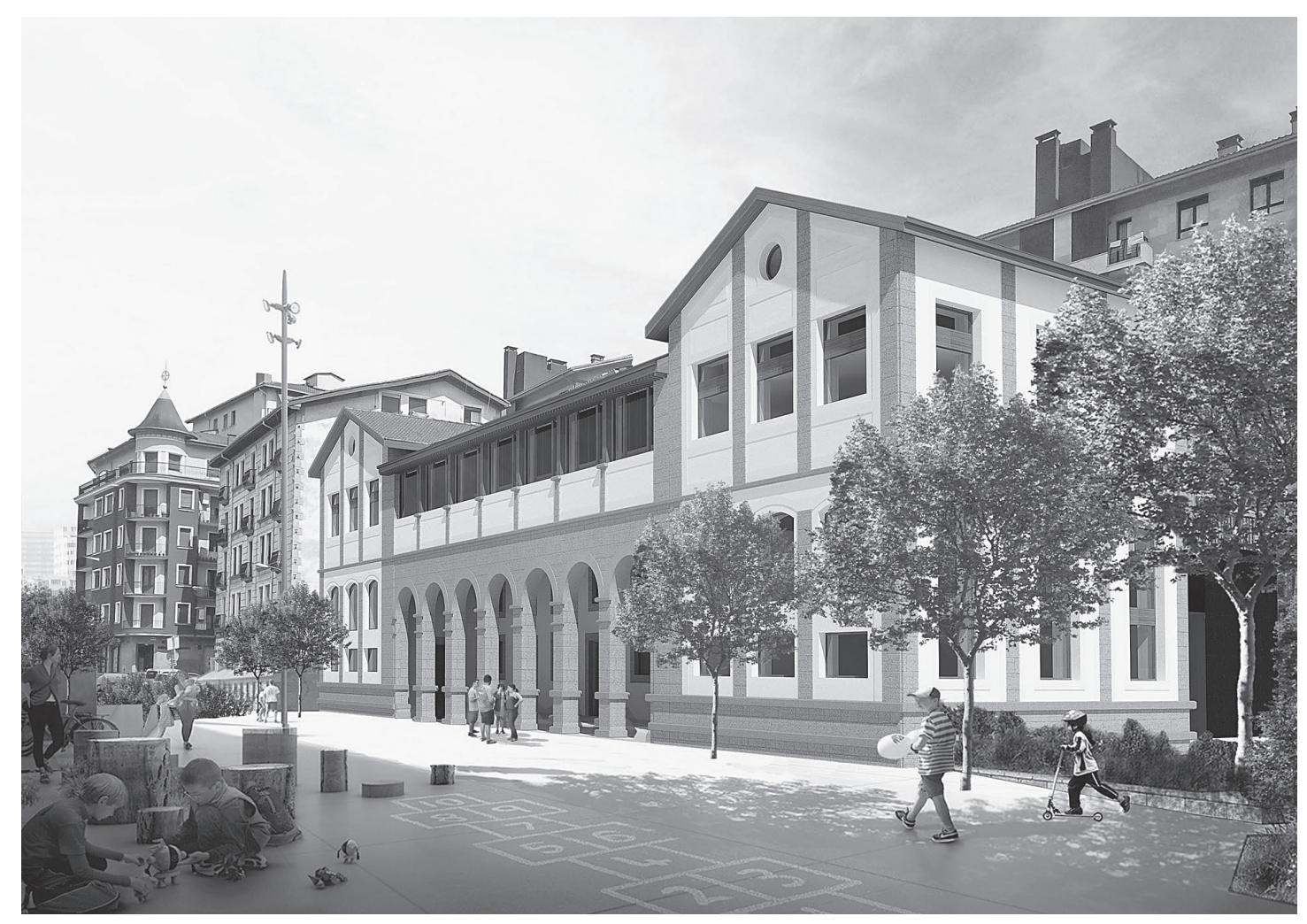

Fig 1. Infografía de la fachada principal hacia la plaza Aita Agirre. JMS arquitectos. 


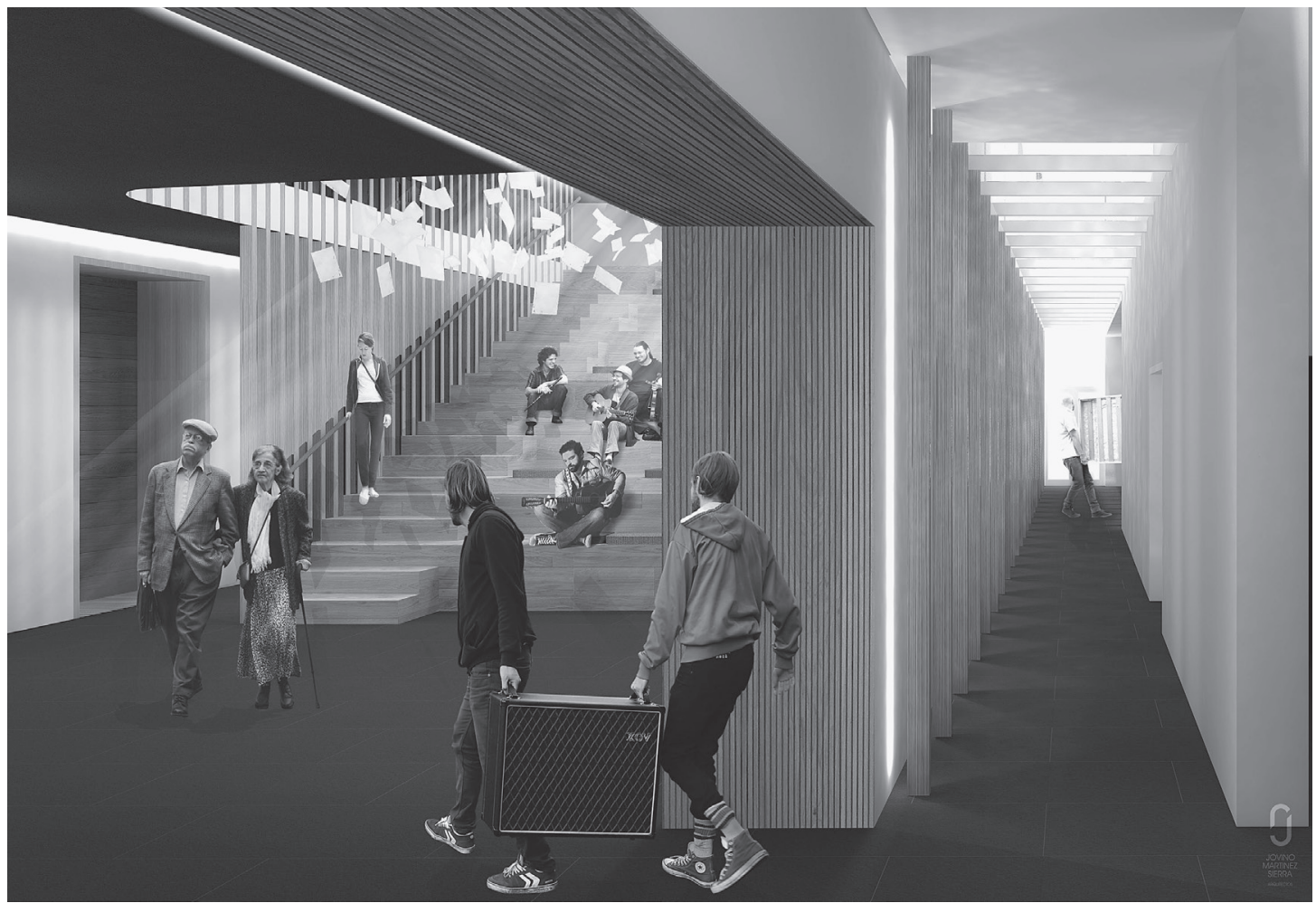

Fig 2. Infografía del espacio interior en planta baja. JMS arquitectos.

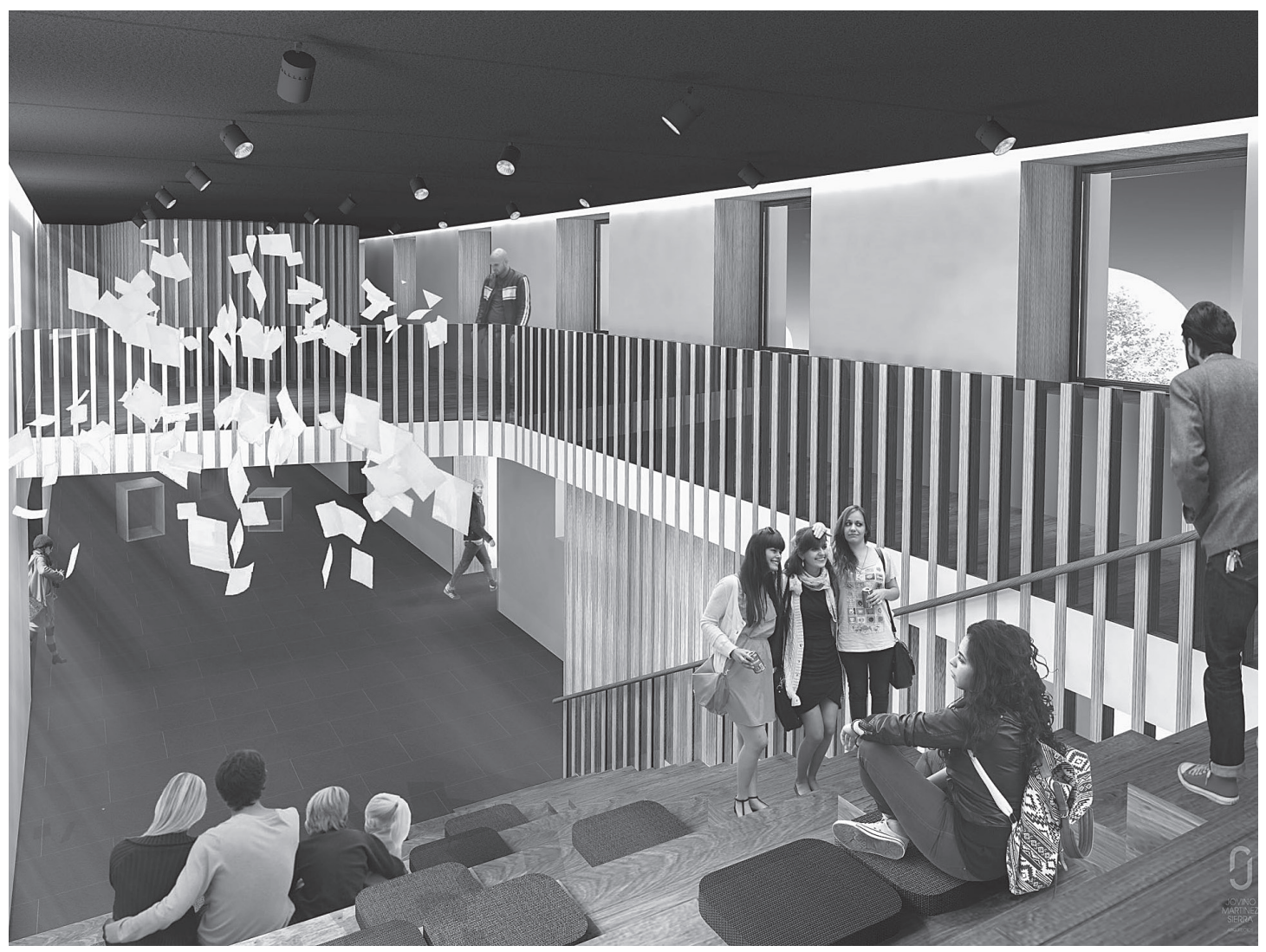

Fig 3. Infografía del graderío entre las plantas baja y primera. JMS arquitectos. 


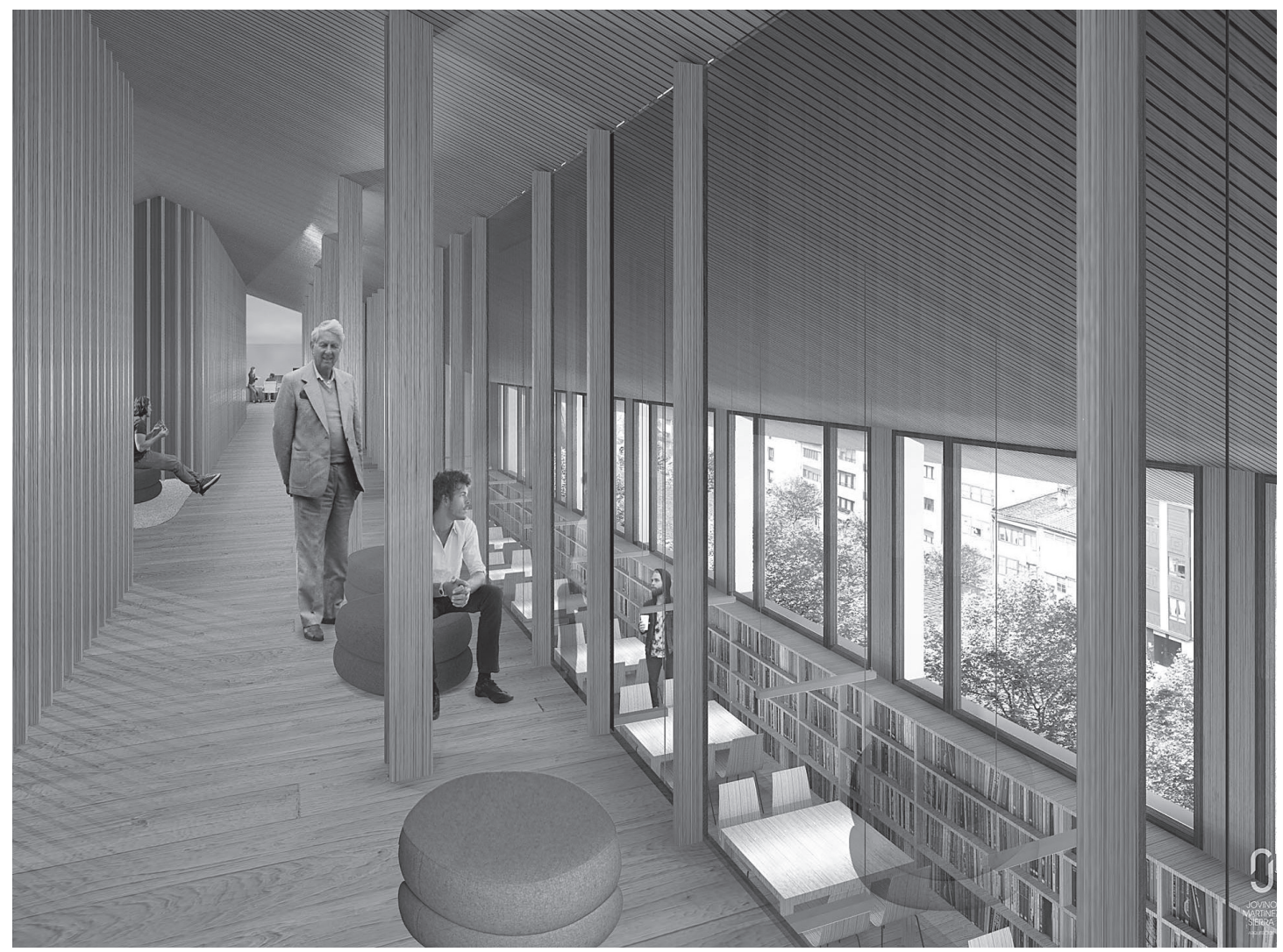

Fig 4. Infografía del bajocubierta con vistas a la biblioteca del edificio y la plaza. JMS arquitectos.

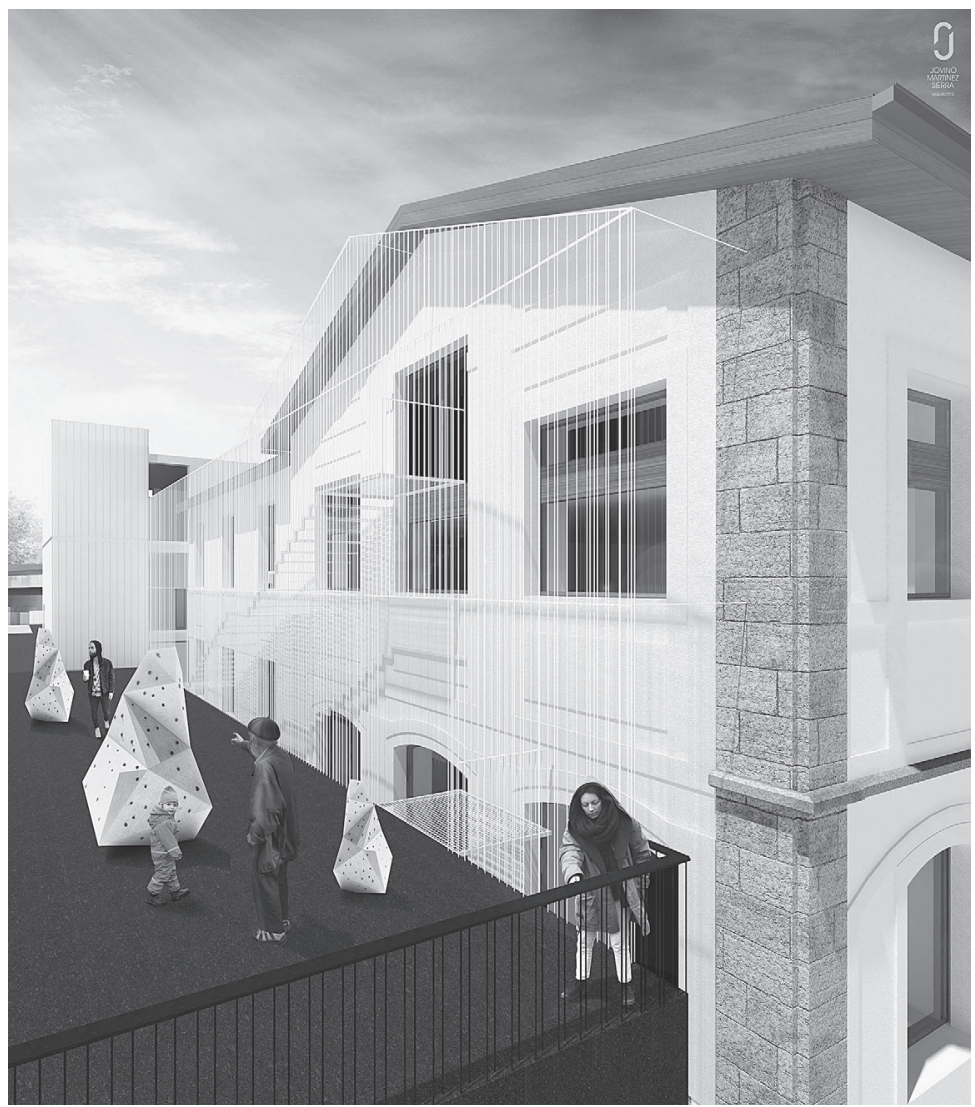

Fig 5. Infografía de la terraza exterior y la fachada trasera del edificio histórico. JMS arquitectos. 


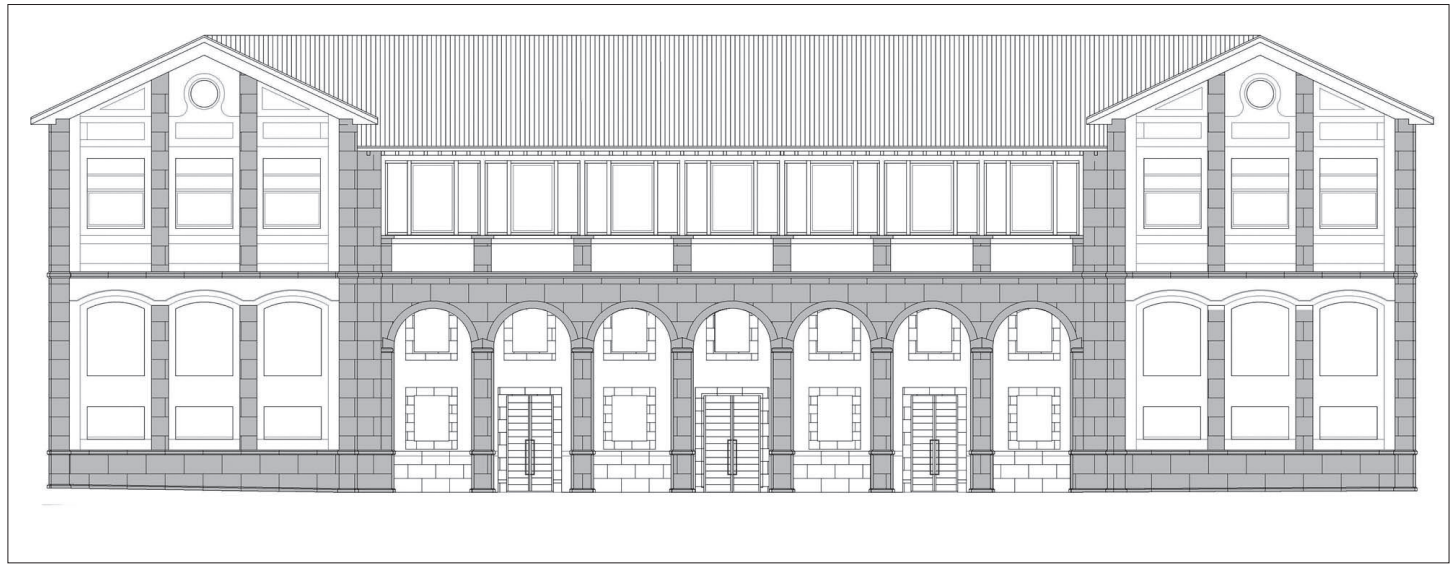

Fig 6. Alzado principal. JMS arquitectos.

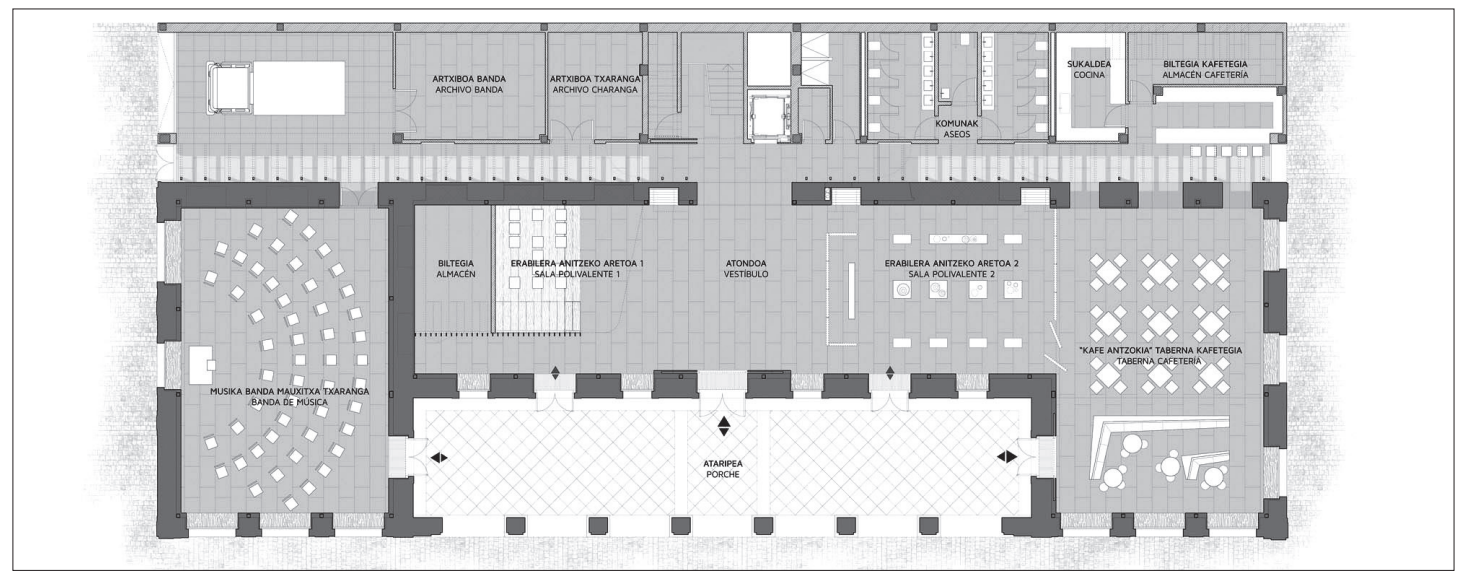

Fig 7. Planta baja. JMS arquitectos.

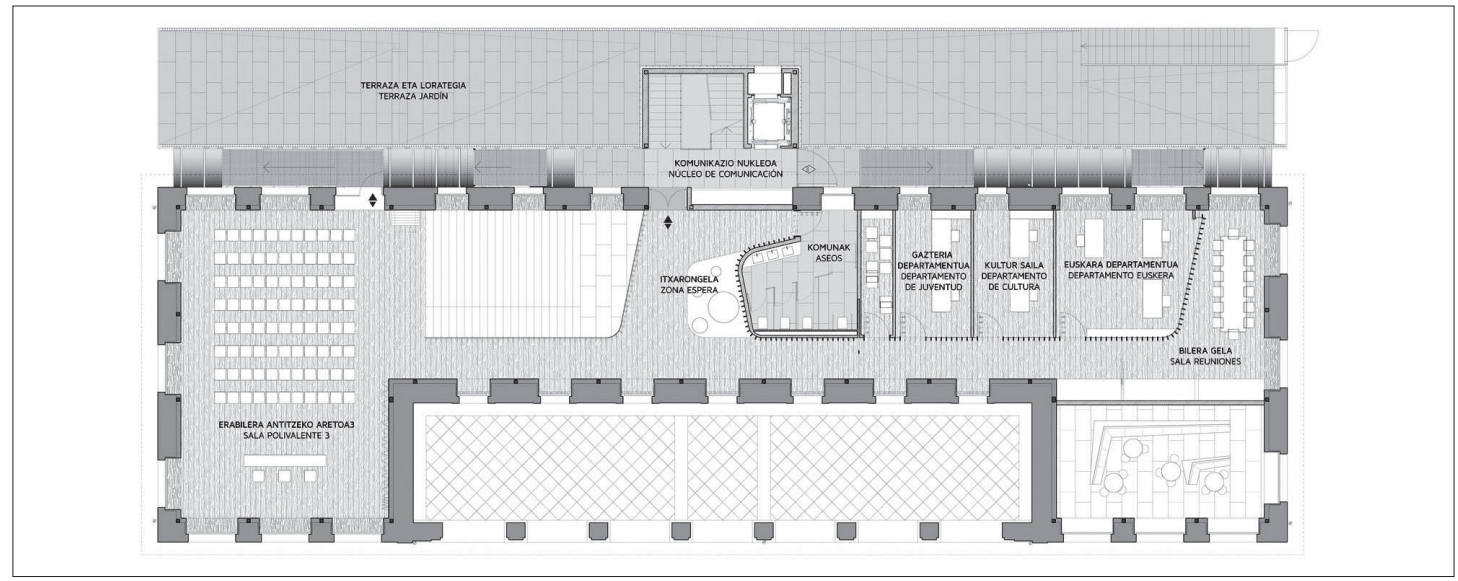

Fig 8. Planta primera. JMS arquitectos. 


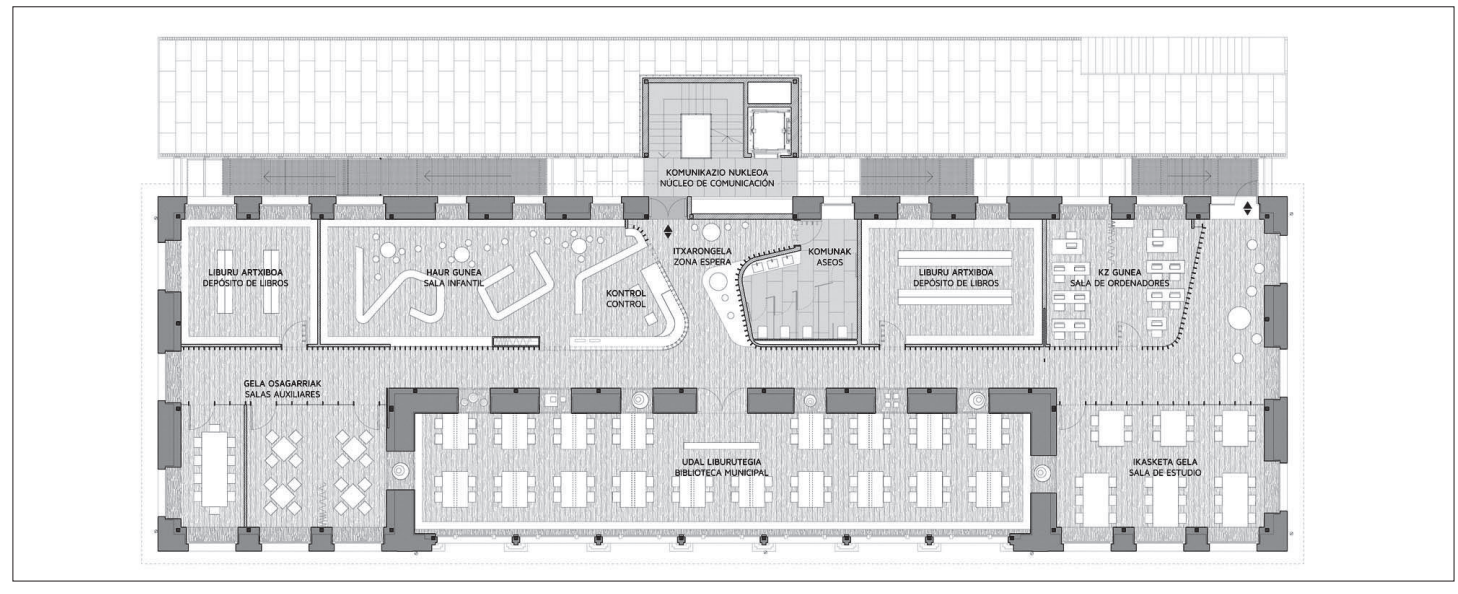

Fig 9. Planta segunda. JMS arquitectos.

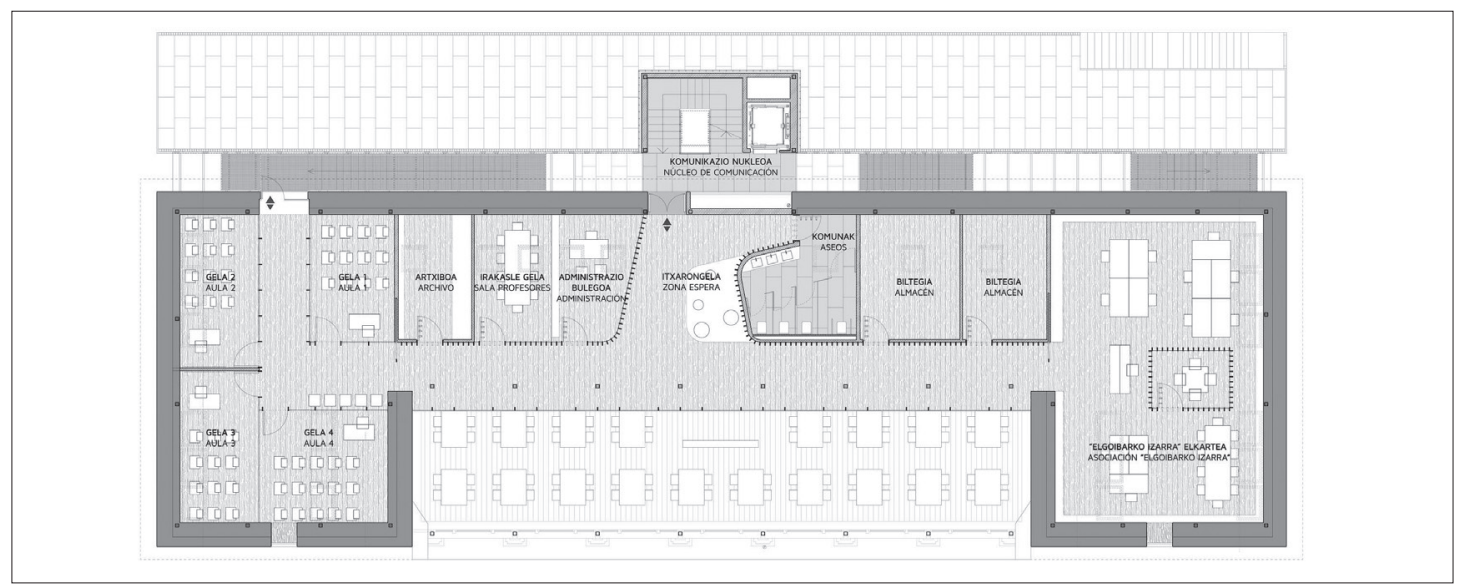

Fig 10. Bajocubierta. JMS arquitectos.

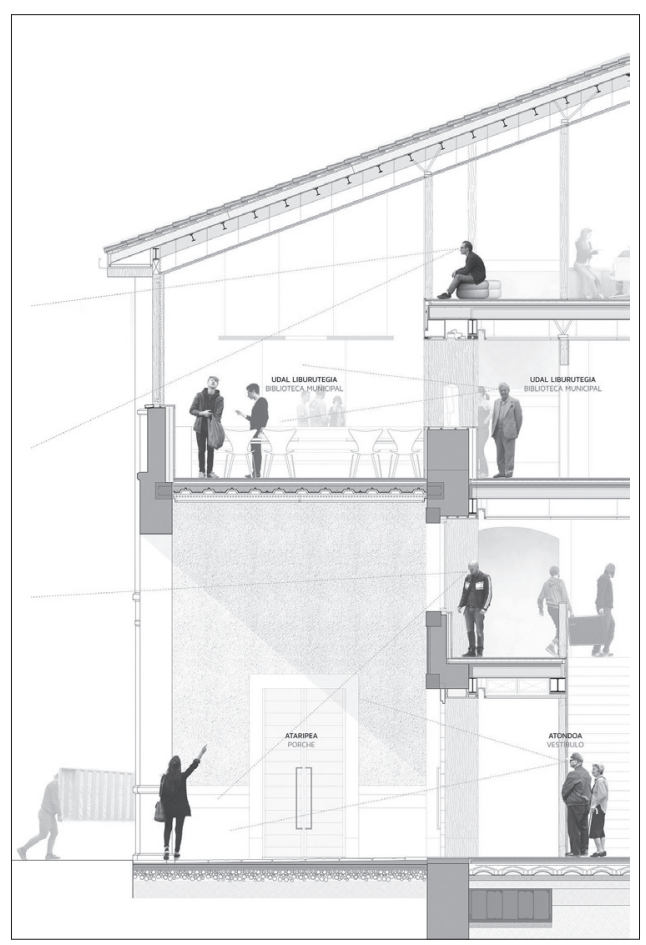

Fig 11. Sección del porche. JMS arquitectos. 